\title{
Detection of spliced and unspliced forms of germline TCR-V $\beta$ transcripts in extrathymic lymphoid sites
}

\author{
Janice L. Abbey, Helen C. O’Neill* \\ School of Biochemistry \& Molecular Biology, Australian National University, Canberra, ACT 0200, Australia \\ Received 3 January 2007; received in revised form 16 July 2007; accepted 18 July 2007 \\ Available online 4 September 2007
}

\begin{abstract}
Germline TCR-V $\beta$ transcription is commonly considered an event coupled with rearrangement of TCR genes in T cells. The extent of germline $\mathrm{V} \beta$ transcription is studied here in a range of cell types and in several mouse strains. A sensitive semi-quantitative RT-PCR method was developed to specifically detect germline and not rearranged transcripts. Germline transcription of a range of different V $\beta$ genes was detected along with rearranged transcripts in bone marrow, thymus, mesenteric lymph node and spleen. Some transcripts were also detected in low level in non-lymphoid tissues including heart, liver and brain. Expression was also studied in the C57BL/6J- $\beta_{2}$ microglobulin $^{-1-}\left(\mathrm{C} 57 \mathrm{BL} / 6 \mathrm{~J}-\beta_{2} \mathrm{M}^{-/-}\right)$mouse model that lacks NK1.1 T cells and predominantly utilises V $\beta 8.2$ in the formation of a TCR. $\beta_{2} \mathrm{M}^{-1-}$ mice, which lack both CD1-dependent NK1.1 T cells and $\mathrm{CD}^{+} \mathrm{T}$ cells, showed germline TCR-V $\beta 8$ transcription in most tissues indicating that germline transcription is not specifically related to CD1-dependent NK1.1 T cells. In many tissues, multiple transcripts were amplified representing both spliced and unspliced forms of germline $\mathrm{V} \beta$. For most V $\beta$ genes, the expression of spliced and unspliced forms was equivalent. Given an abundance of unspliced transcripts, the presence of alternative ORFs encoding a novel protein was investigated within the TCR-V $\beta$ genes. Sequence analysis of ORFs showed only genes with a high level of similarity to TCR- $\beta$. All data reflect the prevalence of germline transcripts in vivo and raise questions about their functional role. (C) 2007 Elsevier Ltd. All rights reserved.
\end{abstract}

Keywords: T cells; T cell receptor; Germline transcription

\section{Introduction}

Germline transcription is the production of mRNA transcripts from either the unrearranged TCR or Ig loci which are in 'germline' configuration. A common view has been that production of germline transcripts is tightly coupled to rearrangement events that take place at these loci to produce a functional $\mathrm{T}$ cell receptor (TCR) or B cell receptor (BCR). If this is the case, one would expect germline transcripts to be produced just prior to VDJ recombination when the chromatin is open and fully accessible to the transcriptional machinery. Contradictory evidence shows germline TCR-V $\beta$ transcripts in mice well before

Abbreviations: ANU, Australian National University; BCR, B cell receptor; $\beta_{2} \mathrm{M}^{-1-}, \beta_{2}$ microglobulin $^{-1-}$; EST, expressed sequence tag; EtBr, ethidium bromide; GL, germline; HSC, hematopoietic stem cell; L, Leader region; ORF, open reading frame; R, rearranged; RT-PCR, reverse transcriptase-PCR; TCR, $\mathrm{T}$ cell receptor; $V$, Variable region gene

* Corresponding author. Tel.: +61 26125 4720; fax: +61 261250313.

E-mail address: Helen.ONeill@ anu.edu.au (H.C. O’Neill). the TCR-V $\beta$ rearrangement event, when TCR rearrangement is blocked (Candeias et al., 1994; Chen et al., 2001; Jolly and O'Neill, 1995), and in tissues that contain cells expressing a fully rearranged TCR (Candeias et al., 1994; Jolly and O'Neill, 1997; O'Neill and Jolly, 1995). This evidence refutes a model for tight linkage between the TCR rearrangement process and the germline transcription event. In addition, germline transcripts were thought to be sterile and non-functional. However, there is evidence that these transcripts may encode and present a TCR-V $\beta$ peptide on the cell surface in the absence of a $C \beta$ region (Abbey et al., 2006; Jolly and O'Neill, 1995). This is a novel finding since the $\mathrm{V} \beta$ domain confers antigen specificity whilst the $C \beta$ domain anchors the receptor in the membrane. This raises many questions about the functional role of germline (GL)-V $\beta$ transcripts within the cell, whether they are translated, and whether they play a functional role in vivo.

Earlier studies on the prevalence of germline (GL) TCR-V $\beta$ transcription identified only GL-V $\beta 8.2$ transcripts in lymphoid tissues and in the lymphoid precursor cell line, C1-V13D (Abbey and O'Neill, 2004; Candeias et al., 1994; Jolly and O'Neill, 
95; O’Neill and Jolly, 1995). Expression of GL-V $\beta$ genes her than V $\beta 8.2$ was then demonstrated in the C1-V13D cell e (Abbey and O'Neill, 2004). An extensive analysis of V $\beta$ ne expression in lymphoid tissues using germline-specific imers has not been attempted. A semi-quantitative study by nen et al. (2001) examined GL-V $\beta$ expression in thymus of AG- $2^{-1-}$ mouse. This experimental system relied entirely on AG- $2^{-1-}$ mice to avoid detection of rearranged transcripts and rward primers were located in the Leader (L) and Variable ) exon of the particular $\mathrm{V} \beta$ gene. Primers would not distinish between rearranged and germline transcripts if the RAG-2 utation was leaky, and gave no indication of the relative levels rearranged versus germline transcripts in any tissue or cell pe. In addition, this semi-quantitative assay did not standardgene expression in relation to a house-keeping gene, but to nomic DNA. Whilst the copy number of each gene may be own, this method does not account for differences between mples in efficiency of RNA extraction and cDNA synthesis. Tissues studies so far have failed to clarify whether GL38.2 transcripts are produced by a single cell type analogous to -V13D or whether they are produced by a range of cells. C113D cell surface markers have been characterised, and cells und to bind anti-NK1.1 antibody (O'Neill, 1992). This raises question of whether C1-V13D is an NK1.1 T cell line, and nether the presence of GL-V $\beta 8.2$ expression in lymphoid tises reflects the presence of NK1.1 T cells, consistent with the ct that some NK1.1 T cells express a mature $\mathrm{T}$ cell receptor $\mathrm{CR}$ ) which preferentially utilises the V $\beta 8.2$ gene (Arase et al., 92). However no information exists on germline TCR-V $\beta 8.2$ inscription in NK1.1 T cells.

A comparison of the expression levels of both germline and arranged V $\beta 8.2$ transcripts involved primers specific for both ader (L)5.1 and L8.2. Analysis was performed in several strains mice including C57BL/6J, DBA/2j and $\beta_{2}$ microglobulin $^{-1-}$ $\left.56 \mathrm{BL} / 6 \mathrm{~J}-\beta_{2} \mathrm{M}^{-1-}\right)$ mice which have limited numbers of K1.1 T cells (Arase et al., 1992; Coles and Raulet, 1994). M forms part of the MHC class I complex and also plays an direct role in the development of NK1.1 T cells through assoation with CD1 (Ohteki and MacDonald, 1994). In $\beta_{2} \mathrm{M}^{-/-}$ ce, CD1 is not expressed and development of CD1-dependent K1.1 T cells is impeded (Bendelac et al., 1997). Comparison germline transcription in $\beta_{2} \mathrm{M}^{-/-}$and parent $\mathrm{C} 57 \mathrm{BL} / 6 \mathrm{~J}$ mice, ould reveal any association between germline transcripts and K1.1 T cells. A semi-quantitative RT-PCR method has been ed here to detect a range of germline TCR-V $\beta$ transcripts cluding GL-V $\beta 8.2$.

\section{Materials and methods}

\section{Animals}

Specific pathogen-free inbred mice were obtained from the hn Curtin School of Medical Research breeding facility at e Australian National University (ANU). Animals were haned and housed according to protocols approved by the Animal perimentation and Ethics Committee at the ANU. C57BL/6J, $3 \mathrm{~A} / 2 \mathrm{j}$ and $\mathrm{C} 57 \mathrm{BL} / 6 \mathrm{~J}-\beta_{2} \mathrm{M}^{-/-}$mutant male and female mice were used at 6-8 weeks of age. Mice were euthanased by $\mathrm{CO}_{2}$ asphixiation for isolation of tissues.

\subsection{RNA isolation}

Total RNA was extracted using the TRIzol reagent (Invitrogen Life Technologies, Mount Waverley, Vic., Australia) according to the manufacturer's instructions. Approximately 1-1.5 U/10 $\mu$ l of RNase Inhibitor (rRNasin R, Promega, Annandale, NSW, Australia) was added to samples prior to storage at $-80^{\circ} \mathrm{C}$. The quality of RNA was determined by electrophoresis on a $1 \%$ agarose gel in $1 \times$ TAE buffer and gels were stained with $5 \mu \mathrm{g} / \mathrm{ml}$ ethidium bromide (EtBr). RNA bands were visualised and photographed under UV illumination and images analysed using NIH Image 1.57 software (National Institutes of Health, Bethesda, MD, USA). Concentration of RNA was determined spectrophotometrically. RNA quality was also assessed using the ratio between the optical density at $260 \mathrm{~nm}$ and $280 \mathrm{~nm}$, where a ratio $>1.8$ is indicative of a pure RNA sample.

Total RNA was treated with RNase-free DNase prior to cDNA synthesis to remove any contaminating DNA that could be amplified in a subsequent RT-PCR. Treatment involved $25 \mu \mathrm{g}$ total RNA, 12.5 units of RNase-free DNase (Promega) and 50 units of RNase Inhibitor (rRNasin R) in $40 \mathrm{mM}$ Tris- $\mathrm{HCl}(\mathrm{pH}$ 7.9), $10 \mathrm{mM} \mathrm{NaCl}, 6 \mathrm{mM} \mathrm{MgCl} 2,10 \mathrm{mM} \mathrm{CaCl}_{2}, 1 \mathrm{mM}$ dithiothreitol in a final volume of $125 \mu$. Samples were incubated at $37^{\circ} \mathrm{C}$ for $30-40 \mathrm{~min}$. DNase-treated total RNA was purified using standard phenol/chloroform extraction and ethanol precipitation procedures.

\subsection{Isolation of genomic DNA}

Genomic DNA was isolated from the phenol phase produced during RNA preparation from TRIzol as described above according to the manufacturer's instructions. The concentration of DNA was determined spectrophotometrically as described above.

\subsection{Reverse transcriptase-polymerase chain reaction}

cDNA was synthesised from total RNA using the First Strand cDNA Synthesis Kit (Amersham Biosciences, Buckinghamshire, UK), according to the manufacturer's instructions. Following cDNA synthesis, the reaction mix was heated for $5 \mathrm{~min}$ to $90^{\circ} \mathrm{C}$ to heat inactivate reverse transcriptase and to denature RNA-cDNA hybrids. cDNA was stored at $-20{ }^{\circ} \mathrm{C}$ until required. Gene-specific oligonucleotides were designed from sequences in the National Center for Biotechnology Information database (NCBI; http://www.ncbi.nlm.nih. gov) using WebANGIS. (http://www1.angis.org.au/pbin/ WebANGIS/wrapper.pl) and Primer 3 (http://www-genome. wi.mit.edu/cgi-bin/primer/primer3_www.cgi) software. Primers were designed to cross exon/intron boundaries in order to specifically detect germline transcripts and were synthesized by Proligo (Lismore, NSW, Australia). Primer sequences, annealing temperatures, and expected product size for each set of oligonucleotide primers are listed in Table 1. 

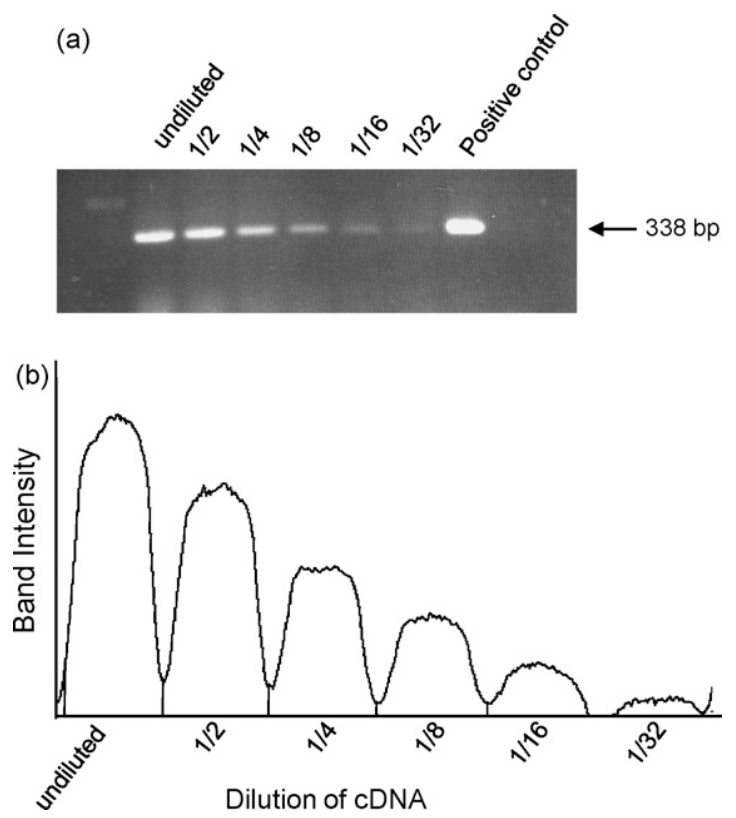

1. Optimisation of semi-quantitative RT-PCR to detect GL-L5.1-V $\beta 8.2$ in 7BL/6J spleen. (a) C57BL/6J spleen cDNA was two-fold serially diluted for PCR using 28 cycles of amplification. The PCR product of each reaction was on a $1.5 \%$ agarose gel and the gel post-stained in EtBr. cDNA dilution and location of the germline band are indicated. Plasmid containing the cloned ne sequence served as a positive control. (b) Densitometric analysis of the 3r-stained gel shown in (a). A digitised photograph of the gel was analysed ng the NIH Image 1.57 Software to measure the intensity of each band on the as a reflection of transcript level.

sentative example of this is shown in Fig. 1, for optimisation RT-PCR to detect GL-L5.1-V $\beta 8.2$ transcripts in spleen of 77BL/6J mice. Cycle number 28 was chosen for amplification this gene. Optimal amplification conditions were determined reach template and each primer set, so that a comparison could made between the expression level of germline and rearranged inscripts across different tissues and strains of mice. Digitised lages of EtBr-stained gels were used for densitometric analysis band intensity. Band intensity was measured using NIH Image 57 software (NIH). Band intensity of the house-keeping gene actin was used to normalise gene expression ratios so that the pression of the same gene could be compared across different mples.

\section{Cloning of PCR products}

Purified PCR products were cloned into pGEM-T Easy Vec- System I (Promega). Insert and vector were combined at a io of approximately 10:1 with $1 \mu \mathrm{l}$ of T4 DNA ligase, $1 \times$ ffer (300 mM Tris- $\mathrm{HCl}, \mathrm{pH} 7.8,100 \mathrm{mM} \mathrm{MgCl} 2,100 \mathrm{mM}$ ГT, $5 \mathrm{mM}$ ATP) and $1 \mu \mathrm{l} 4$ DNA ligase (3 Weiss units $/ \mathrm{ml}$ ) in $10 \mu \mathrm{l}$ reaction volume. The reaction components were mixed d incubated overnight at $4{ }^{\circ} \mathrm{C}$. Transformation of bacteria th ligation mix was performed using calcium chloride preitation and JM109 Escherichia coli cells (Promega). Cells $\mathrm{d}$ ligation mix were combined on ice prior to heat shock $42^{\circ} \mathrm{C}$ for $45 \mathrm{~s}$ followed by chilling. Cells in SOC medium LB medium were incubated at $37^{\circ} \mathrm{C}$ for $1 \mathrm{~h}$ with shaking.
Aliquots of transformed cells were plated on to LB plates containing $100 \mu \mathrm{g} / \mathrm{ml}$ ampicillin, $20 \mu \mathrm{l}$ of $50 \mathrm{mg} / \mathrm{ml}$ stock solution of 5'bromo-4-chloro-3-indoly-beta-D-galactopyranside (X-gal) and $10 \mu \mathrm{l}$ of $1 \mathrm{M}$ isopropyl-beta-D-thiogalactoside (IPTG). Plates were incubated at $37^{\circ} \mathrm{C}$ overnight, and colonies containing the appropriate insert identified based on the blue/white selection system of $\alpha$-complementation. Transformed $E$. coli colonies were picked and grown in overnight cultures in LB containing ampicillin $(100 \mu \mathrm{g} / \mathrm{ml})$. Purification of plasmid DNA from cells was achieved using the QIAprep Spin Miniprep Kit (Qiagen, Doncaster, Vic., Australia) according to the manufacturer's instructions. The purified plasmid was stored at $-20^{\circ} \mathrm{C}$. Plasmid concentration and purity was determined spectrophotometrically.

\subsection{DNA sequencing}

Sequencing was conducted using the ABI PRISM BigDye terminator Cycle Sequencing Ready Reaction Kit (Applied Biosystems, Foster City, CA) according to the manufacturer's instructions for $10 \mu \mathrm{l}$ reactions. Reactions comprised approximately 200-500 ng of double-stranded DNA or 30-90 ng of purified PCR product. Primers used for PCR amplification were also used to initiate sequencing reactions. The cycling program used was: 25 cycles of cycle denaturation $\left(96^{\circ} \mathrm{C}\right.$ for $30 \mathrm{~s}$ ), annealing ( $15 \mathrm{~s}$ at the selected annealing temperature), and extension $\left(60^{\circ} \mathrm{C}\right.$ for $\left.4 \mathrm{~min}\right)$. Sequencing products were purified with standard ethanol precipitation methods to remove excess unincorporated terminators, the sample was air-dried and stored at $-20^{\circ} \mathrm{C}$. Samples were analysed in an automated DNA sequencer (Applied Biosystems; ABI Model 377) in the Biomolecular Resources Facility (ANU).

\subsection{Bioinformatic analysis}

TCR-V $\beta$ exon and intron sequences were obtained both experimentally and from the NCBI database (http://www.ncbi.nlm.nih.gov). The Basic Local Alignment Search Tool (BLAST) was used. 'Blastn' was used to compare nucleotide sequence in either the ' $n r$ ' database (non-redundant GenBank CDS translations, PDB, SwissProt, PIR and PRF) or the mouse Expressed Sequence Tag (EST) database. 'Blastp' was used to compare protein sequences within the NCBI database, at times using the 'short nearly exact matches' searching tool. Nucleotide sequence was sometimes compared with the protein database using 'translated query versus protein database' (BlastX). The level of similarity between the input sequence and the database was assessed. Alternative open-reading frame analysis was conducted using NCBI 'ORF finder' (http://www.ncbi.nlm.nih.gov/gorf/gorf.html) which examines a nucleotide sequence in all six open-reading frames. Multiple sequence alignments were performed using either experimental data or sequences from the NCBI database and aligned in MacVector version 7.1 (Oxford Molecular Group) using Clustal W (Thompson et al., 1994). 


\section{Results}

\subsection{Development of a semi-quantitative assay for detection of germline TCR-V $\beta 8.2$ transcripts in murine tissues}

Germline TCR-V $\beta 8$ transcription studies have predominately used Southern blot analysis to detect amplification products from RT-PCR (Jolly and O’Neill, 1997; O’Neill, 1992; O'Neill and Jolly, 1995). An improved RT-PCR method was developed to detect low levels of GL-V $\beta 8.2$ transcription on EtBr-stained gels (Abbey and O'Neill, 2004). The method simplified the detection system, but did not enhance quantitation, and results could only be interpreted as present or absent. Product amplification of the same gene could not be compared between different tissue samples. Real-time PCR is a quantitative technique, readily applicable to comparison of gene expression between tissue samples. It depends on amplification of a PCR product of less than $100 \mathrm{bp}$ (Bustin, 2000). Real-time PCR methods are highly sensitive and reproducible, but are not applicable to studies on germline transcription used here. In this study it has been necessary to semi-quantitate spliced and unspliced transcripts and to distinguish V $\beta 8.2$ transcripts initiated from either L5.1 or L8.2. For these purposes, the length of the product needed to distinguish transcripts requires an amplicon much greater than a $100 \mathrm{bp}$ product, which is the upper size product limit for real-time PCR.

To distinguish GL transcripts, the amplicon included the $\mathrm{L}$, $\mathrm{V} \beta$ and the $3^{\prime} \mathrm{UTR}$ regions. This is essential since the $\mathrm{L}$ for the V $\beta 8$ region can be either L5.1 or L8.2 (Abbey and O'Neill, 2004; Chou et al., 1987), the V $\beta$ region must be amplified since this is the gene under study, and the $3^{\prime}$ UTR must be included to demonstrate that amplification is generated from a germline and not a rearranged transcript. In addition, spliced and unspliced forms of GL-V $\beta$ transcripts have been identified in C1-V13D, and their identification requires intronic regions in the amplification product to determine the form of the transcript (Abbey and O'Neill, 2004). As a result, most germline PCR products needed to detect GL transcripts are at least $300 \mathrm{bp}$ in length. For this reason, a semi-quantitative RT-PCR assay was developed to detect and amplify splice variants of GL-V $\beta$ genes in multiple murine tissues. Optimal cycle parameters were determined for each cDNA sample and for each primer set. In order to determine relative gene expression levels, a control house-keeping gene, $\beta$-actin, was amplified along with test genes. Furthermore, this procedure has been tailored to detect only germline and not rearranged transcripts through the use of primers that cross exon/intron boundaries. It has also been designed to detect RNA and not contaminating genomic DNA through DNAse treatment of RNA prior to amplification.

\subsection{Semi-quantitative analysis of germline and rearranged} TCR-V $\beta 8.2$ gene expression in $\beta_{2} M^{-/-}$mice

Germline and rearranged V $\beta 8.2$ transcription was measured in multiple tissues. Rearranged transcripts of L5.1-V $\beta 8.2$ were detected in thymus, mesenteric lymph node and spleen of $\beta_{2} \mathrm{M}^{-/-}$mice (Fig. 2). This observation has been attributed to the strong L5.1 promoter (Chou et al., 1987; Sutton et al., 1998), and may account for the L5.1-V $\beta 8.2$ product predominating in tissues in comparison to L8.2-V $\beta 8.2$. This result was expected since these tissues contain mature $\mathrm{T}$ cells. Rearranged L8.2-V $\beta 8.2$ transcripts were also detected with different primers in thymus, mesenteric lymph node, spleen but not bone marrow or kidney of both C57BL/6J and $\beta_{2} \mathrm{M}^{-1-}$ mice. Kidney was used as a negative control in Fig. 2.

GL-L5.1-V $\beta 8.2$ transcripts were detected in all lymphoid tissues analysed. However, varying levels were detected between tissues and between the different mouse strains. The presence of germline transcripts in $\beta_{2} \mathrm{M}^{-/-}$mice confirms that GL-V $\beta 8.2$ products are not a product only of CD1-dependent NK1.1 T cells, and must be produced by other cells present within these tissues. GL-L8.2-Vß8.2 transcription was also observed in lymphoid tissues from both mouse strains. The level of GL-L8.2-V $\beta 8.2$ transcripts also varied across tissues. Unlike the rearranged form, GL-L8.2-V $\beta 8.2$ transcripts were detected in bone marrow of both C57BL/6J and $\beta_{2} \mathrm{M}^{-/-}$mice.

Expression ratios of both GL-L5.1-V $\beta 8.2$ and GL-L8.2$\mathrm{V} \beta 8.2$ relative to $\beta$-actin were calculated and are shown in Fig. 2. GL-L5.1-V $\beta 8.2 / \beta$-actin expression ratios were similar in all tissues of C57BL/6J and $\beta_{2} \mathrm{M}^{-/-}$mice. GL-L8.2-V $\beta 8.2 / \beta$ actin expression ratio was six-fold higher in the bone marrow of $\beta_{2} \mathrm{M}^{-1-}$ mice compared with $\mathrm{C} 57 \mathrm{BL} / 6 \mathrm{~J}$ mice and four-fold lower in spleen. To some extent this change was also reflected in the levels of rearranged L5.1-V $\beta 8.2$ and L8.2-V $\beta 8.2$ transcripts in these tissues. This change in expression level may suggest a need for MHC Class I molecules which may be important for development within bone marrow or migration of cells out of that site. For example, bone marrow could be a developmental niche for these cells that later localise in the spleen.

Expression levels in thymus were generally similar between the two mouse strains. Lower levels of rearranged L8.2-V $\beta 8.2$ transcripts in the spleen of $\beta_{2} \mathrm{M}^{-1-}$ mice were also associated with decrease in germline transcripts. For rearranged transcripts, this decrease reflects loss of $\mathrm{CD}^{+} \mathrm{T}$ cells in the periphery of $\beta_{2} \mathrm{M}^{-/-}$mice due to a loss of MHC Class I expression in thymus (Zijlstra et al., 1990).

Increased levels of GL-V $\beta 8.2$ transcripts were observed in the bone marrow and decreased transcripts in spleen of $\beta_{2} \mathrm{M}^{-I-}$ mice, together with a decrease in rearranged L8.2-V $\beta 8.2$ transcripts in spleen. This could reflect either different cell numbers or different levels of transcription. To examine this possibility, flow cytometry was used to compare numbers of $\mathrm{V} \beta 8.2^{+} \mathrm{C} \beta^{-}$ cells in both thymus and bone marrow as detected previously (O'Neill and Jolly, 1995). In the thymus, similar percentages of $\mathrm{V} \beta 8^{+} \mathrm{C} \beta^{-}$cells were detected in $\mathrm{C} 57 \mathrm{BL} / 6 \mathrm{~J}(3.7 \%)$ and C56BL/6J- $\beta_{2} \mathrm{M}^{-1-}(4.4 \%)$ mice. A similar trend was observed in the bone marrow, with $\mathrm{C} 57 \mathrm{BL} / 6 \mathrm{~J}$ mice displaying a $\mathrm{V} \beta 8^{+} \mathrm{C} \beta^{-}$ population comprising $1.5 \%$ of cells with $0.88 \%$ in $\beta_{2} \mathrm{M}^{-/-}$ mice (data not shown). These results suggest that differences observed in the level of germline transcription may not be a reflection of cell number, but a difference in transcript level. The presence of $\mathrm{V} \beta 8^{+} \mathrm{C} \beta^{-}$cells in $\beta_{2} \mathrm{M}^{-/-}$mice confirms the transcriptional data that germline $V \beta 8$ transcripts are not 

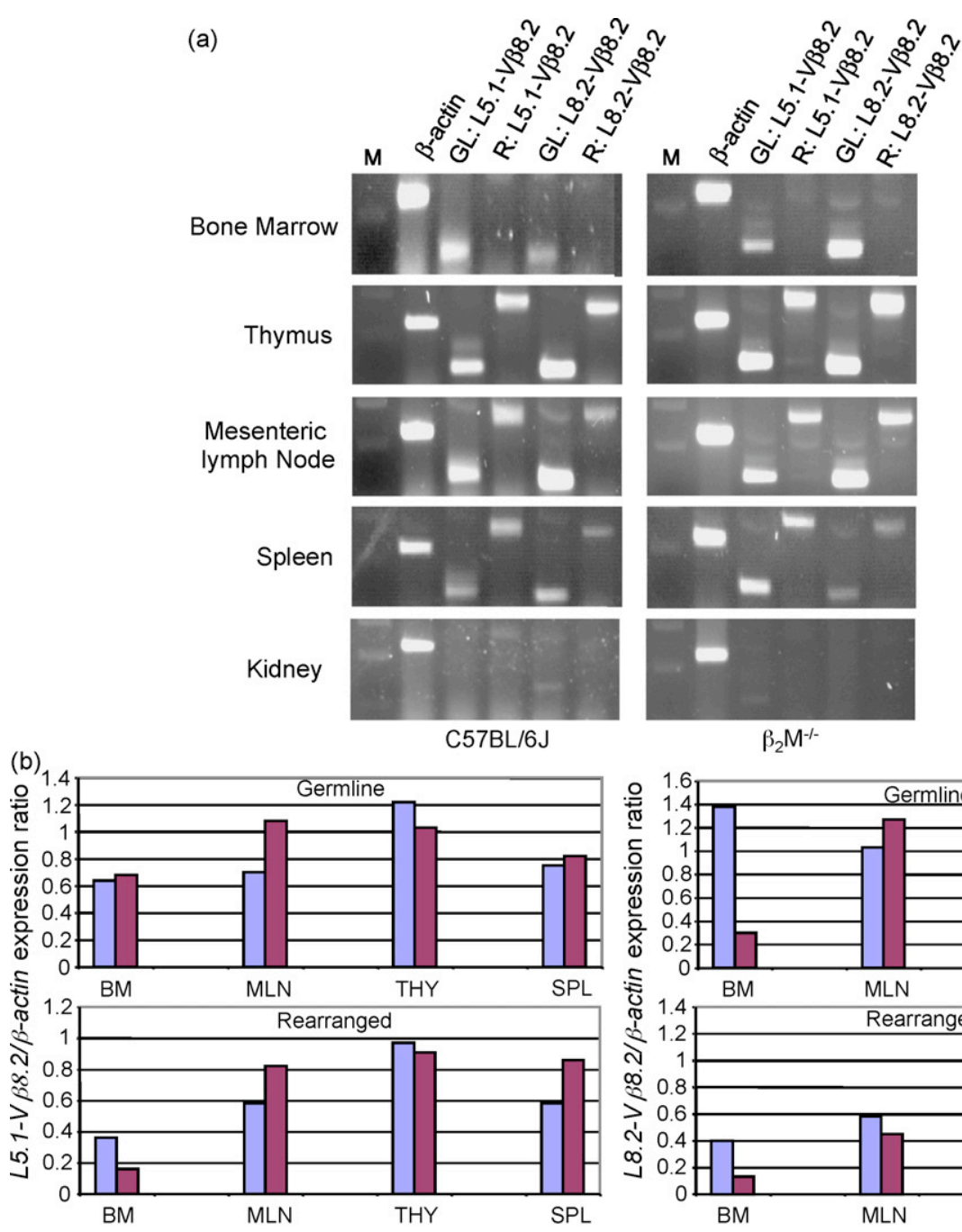

$\beta_{2} \mathrm{M}^{-1-}$

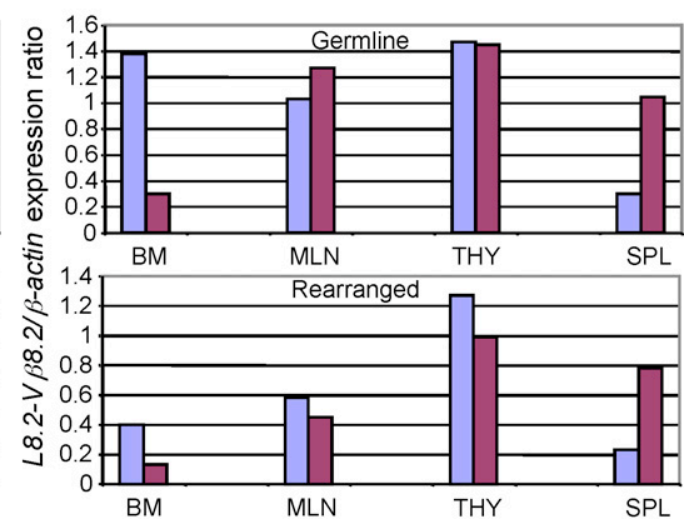

2. Expression of germline and rearranged TCR-V $\beta 8.2$ transcripts in lymphoid tissues from C57BL/6J and $\beta_{2} \mathrm{M}^{-/-}$mice using a semi-quantitative RT-PCR

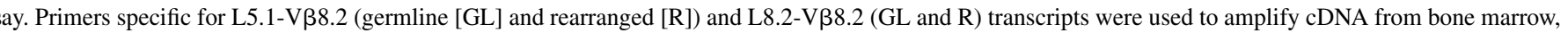
mus, mesenteric lymph node and spleen. The control gene used for semi-quantitation was $\beta$-actin. Kidney cDNA from both mouse strains was used as a negative trol. Samples were amplified at a pre-determined optimal cycle number which ensured that amplification was occurring within the linear range. (a) The products PCR reactions were electrophoresed on a 1.5\% agarose gel and post-stained in EtBr. M = marker lane (Gene Ruler $1 \mathrm{~kb}$ DNA Ladder). (b) Band intensity of plification products was obtained using densitometry. A semi-quantitative estimate of gene expression was made relative to $\beta$-actin by calculating relative band ensities. Values are represented as V $\beta 8.2 / \beta$-actin expression ratio in bone marrow (BM), mesenteric lymph node (MLN), thymus (THY) and spleen (SPL). Data ints from $\beta_{2} \mathrm{M}^{-1-}$ and $\mathrm{C} 57 \mathrm{BL} / 6 \mathrm{~J}$ mice are indicated by light and dark bars, respectively.

ked to the presence of CD1-dependent NK1.1 T cells in $o$.

\section{Analysis of TCR-VB8.2 expression in non-lymphoid sues}

Non-lymphoid tissues including liver, brain, heart and kid$\mathrm{y}$ from C57BL/6J and $\beta_{2} \mathrm{M}^{-/-}$mice were also tested for the esence of germline and rearranged V $\beta 8.2$ transcripts. Low vel GL-L8.2-Vß8.2 transcription was detected in the liver of th mouse strains (Fig. 3), and GL-L5.1-V $\beta 8.2$ was detected $\beta_{2} \mathrm{M}^{-1-}$ mice. However, rearranged V $\beta 8.2$ transcripts were $t$ detected in liver, suggesting that cells other than mature $\mathrm{T}$ lls are responsible for germline transcription. Low levels of rmline L8.2-V $\beta 8.2$ were observed in the brain of $\beta_{2} \mathrm{M}^{-/-}$ ce. Very low levels of germline but not rearranged transcripts of both L5.1-V $\beta 8.2$ and L8.2-V $\beta 8.2$ were also detected in heart. Since rearranged transcripts were not observed in any of these tissues, it is assumed that GL-V $\beta 8.2$ transcripts arose from non$\mathrm{T}$ cells.

\subsection{Comparison of germline TCR-V $\beta$ expression in C57BL/6J and DBA/2j mice}

The expression of multiple germline TCR-V $\beta$ genes has been reported in RAG- $2^{-1-}$ mouse thymus (Chen et al., 2001) but the primers used did not discriminate between germline or rearranged transcripts and detection of only germline transcripts relied on mutation in the RAG gene. That study concluded that the level of germline transcription for each $V \beta$ gene was related to the individual promoter strength of each $\mathrm{V} \beta$ gene and did not consider the possibility that simultaneous transcription of 

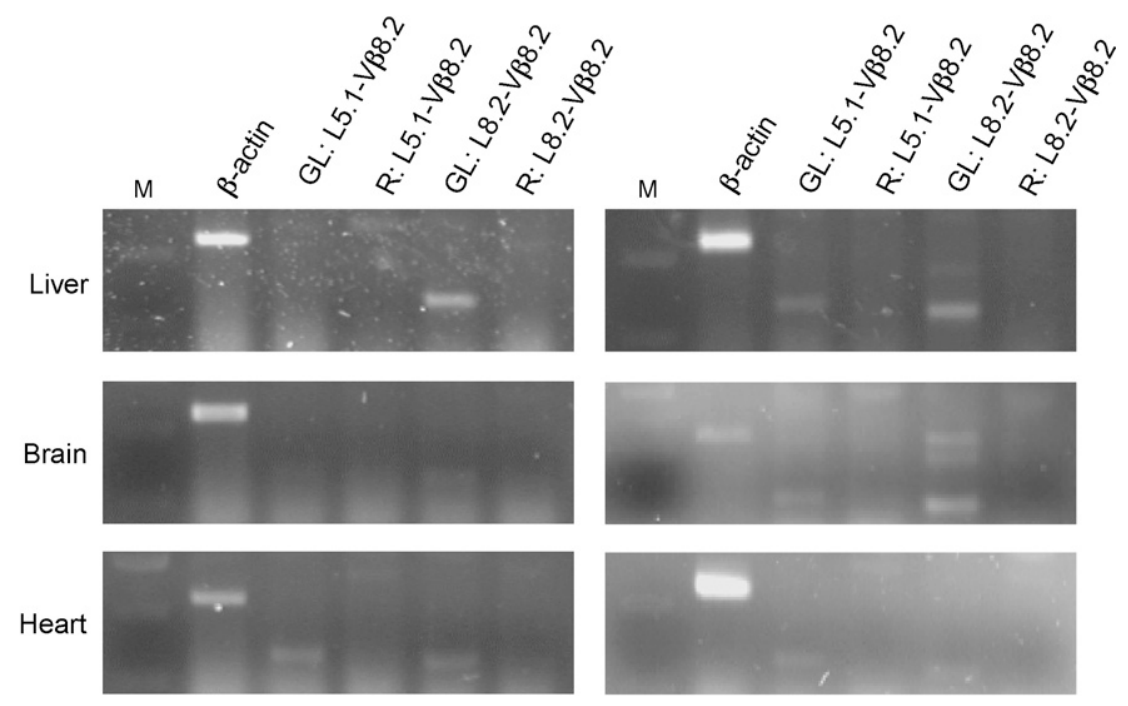

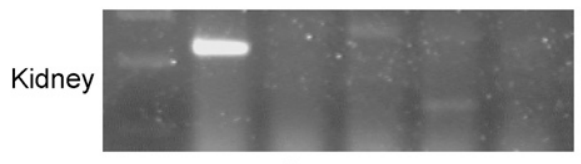

C57BL/6J

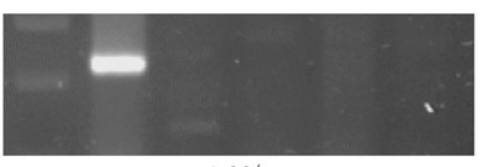

$\beta_{2} \mathrm{M}^{-/-}$

Fig. 3. Expression of germline and rearranged TCR-V $\beta 8.2$ transcripts in non-lymphoid tissues from C57BL/6J and $\beta_{2} \mathrm{M}^{-1-}$ mice. Primers specific for L5.1-V $\beta 8.2$ (germline $[\mathrm{GL}]$ and rearranged $[\mathrm{R}]$ ) and L8.2-V $\beta 8.2$ (GL and R) were used to amplify cDNA from liver, brain, heart and kidney. The control gene used for semiquantitation was $\beta$-actin. Samples were amplified at a pre-determined optimal cycle number which ensured that amplification was occurring within the linear range. The products of PCR reactions were electrophoresed on a 1.5\% agarose gel and post-stained in EtBr. M=marker lane (Gene Ruler 1 kb DNA Ladder).

germline and rearranged TCR-V $\beta$ genes could occur in mature T cells.

A study was therefore conducted to examine relative levels of germline transcription in multiple lymphoid tissues of C57BL/6J and DBA/2j mice using an assay that detected only germline transcripts in bone marrow, thymus, mesenteric lymph node and spleen. RT-PCR was conducted using primers specific for GL$\mathrm{V} \beta 8.1,2.1,5.1,5.2,8.3,13.1$ and the two forms of $\mathrm{V} \beta 8.2$. In C57BL/6J mice, all lymphoid tissues displayed germline expression of each V $\beta$ gene tested (Fig. 4). The transcript level for individual genes varied between tissues, while GL-L5.1-V $\beta 8.2$ expression was high in all tissues except thymus. High expression of GL-L5.1-V $\beta 8.2$ could be attributed to the strength of the L5.1 promoter, which has been reported previously (Chou et al.,

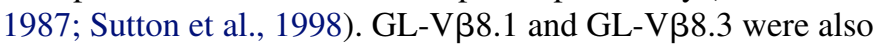
produced in high levels in all lymphoid tissues in comparison with other V $\beta$ genes and so germline transcription in lymphoid tissues was not a specific phenomenon related to only V $\beta 8.2$, but was characteristic of many $\mathrm{V} \beta$ genes. Also notable was the presence of two bands after electrophoresis of RT-PCR products. When these bands were excised, purified, cloned and sequenced, the larger band was found to represent an unspliced transcript consisting of the $\mathrm{L}$ sequence, the intron and the adjacent V $\beta$ exon, while the smaller product represented a spliced form of the transcript, lacking the intron. The sequence of representative spliced and unspliced V $\beta 8.2$ transcripts derived from the C1-V13D spleen derived cell line is shown in Fig. 5. However, production of both spliced and unspliced transcripts was confirmed by sequencing for each of the V $\beta 2.1, \mathrm{~V} \beta 5.1, \mathrm{~V} \beta 5.2$, and V $\beta 8.3$ genes.
While the amplification of products of different size by RT-PCR has been noted previously (Chen et al., 2001), these products were not characterised by sequencing as spliced and unspliced forms. Here, the level of these two forms was shown to vary for each transcript. In some cases, the unspliced form predominated, and for other $\mathrm{V} \beta$ genes, the spliced form was expressed in higher levels. As expected, only one product was detected for GL-L5.1-V $\beta 8.2$, comprising the upstream L of V $\beta 5.1$ and the V $\beta 8.2$ exon (Fig. 5). Ratios of spliced to unspliced products for different $\mathrm{V} \beta$ genes is shown in Fig. 4. While this was approximately one for most genes in most tissues, V $\beta 8.3$ and V $\beta 13.1$ exist predominately in unspliced form in spleen and mesenteric lymph node, respectively.

The expression of germline $\mathrm{V} \beta$ genes was also studied in $\mathrm{DBA} / 2 \mathrm{j}$ mice, the parent strain of the $\mathrm{C} 1-\mathrm{V} 13 \mathrm{D}$ cell line. Both spliced and unspliced forms of GL-V $\beta 8.2$ were detected in DBA/2j mice (Fig. 6), although germline $\mathrm{V} \beta$ transcripts were not as widely expressed as in lymphoid tissues of C57BL/6J mice. DBA/2j bone marrow showed very little germline $\mathrm{V} \beta$ gene expression. Thymus showed expression of GL-V $\beta 6.1$, GL-V $\beta 8.3$ and GL-V $\beta 7.1$. Mesenteric lymph node showed only GL-V $\beta 8.3$ and GL-V $\beta 8.1$, while spleen displayed GL-V $\beta$ expression for all genes analysed. It is interesting that the highest and most diverse range of transcripts was seen in spleen, the site from which $\mathrm{C} 1-\mathrm{V} 13 \mathrm{D}$ was isolated. In addition, a notable decrease in GL-V $\beta 8.2$ was observed in the spleen of $\beta_{2} \mathrm{M}^{-/-}$ mice in comparison to wild-type mice (Fig. 2). This could reflect the presence of a cell subset in spleen that contributes predominantly to GL-V $\beta$ gene expression. This subset could produce 
(a)

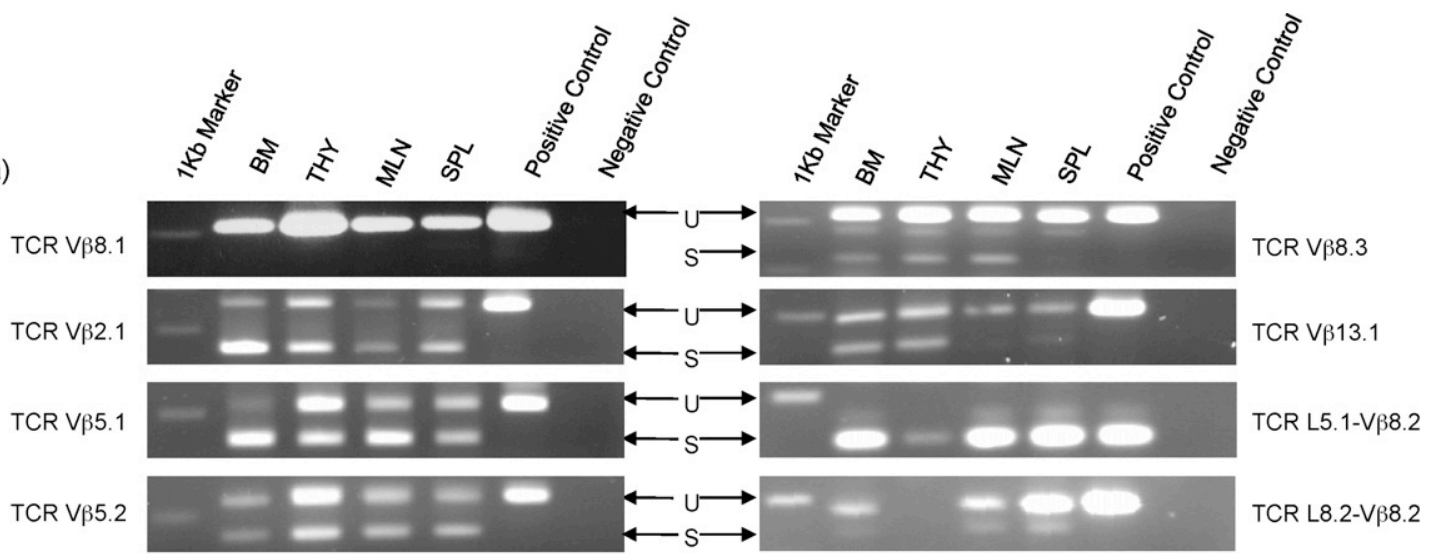

(b)
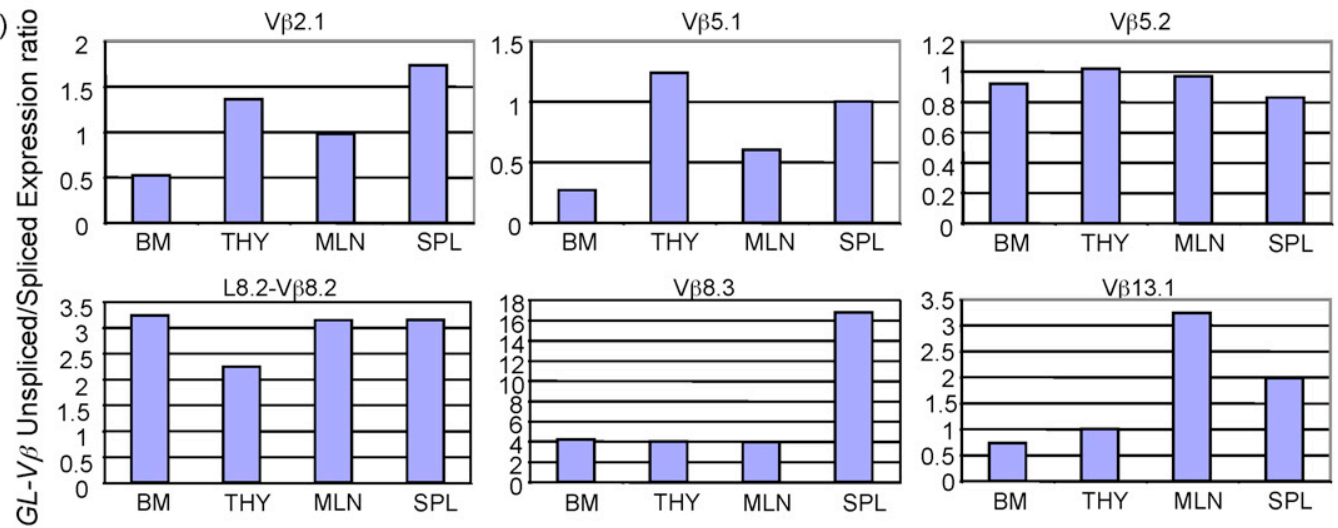

5. A range of germline TCR-V $\beta$ genes are expressed in lymphoid tissues of C57BL/6J mice. RT-PCR products were generated from cDNA using primer sets ich amplify only germline and not rearranged transcripts encoded by a range of different TCR-V $\beta$ genes. Control reactions contained genomic DNA (positive trol) and no DNA (negative control). Genomic DNA used in control reactions was derived from C1V-13D, although cDNA from lymphoid tissues was used a control in the case of V $\beta 8.2$ transcripts due to unusual splicing of V $\beta 8.2$ to L5.1, and the location of L8 primers. (a) The products of PCR reactions were ctrophoresed on a $1.5 \%$ agarose gel and post-stained in EtBr. U: unspliced; S: spliced; BM: bone marrow; THY: thymus; MLN: mesenteric lymph node; SPL: een. Gene Ruler $1 \mathrm{~kb}$ DNA Ladder was used as a marker. (b) Comparison of expression levels of spliced and unspliced germline V $\beta 8.2$ in C57BL/6J mice. The ensity of amplification products shown on EtBr-stained gels was analysed using densitometry. An unspliced/spliced expression ratio was generated for each $\mathrm{V} \beta$ ne. Values are not shown for V $\beta 8.1$ or L5.1-V $\beta 8.2$ since these genes did not produce a spliced or unspliced form, respectively. For V $\beta 8.2$, data shown represents mline L8.2-Vß8.2 unspliced/spliced expression ratio for bone marrow (BM), mesenteric lymph node (MLN), thymus (THY) and spleen (SPL).

$-\mathrm{V} \beta 8.2$, as well as other GL-V $\beta$, consistent with the range GL-V $\beta$ expression identified in the $C 1-V 13 D$ cell line.

\section{Verification of spliced and unspliced forms of $G L-V \beta$}

Multiple GL-V $\beta 8.2$ transcripts have been identified here for th $\mathrm{C} 57 \mathrm{BL} / 6 \mathrm{~J}$ and DBA/2j tissues as seen previously for the mature $\mathrm{T}$ cell line, C1-V13D. Bands representing individ1 RT-PCR products were excised from agarose gels, purified $\mathrm{d}$ either sequenced directly or cloned into a T-overhang vec(pGEM-T) for sequencing. Sequence analysis confirmed at multiple PCR products represent unspliced and spliced rms of GL-V $\beta$ transcripts. Sequence data is shown diagramatically in Fig. 7. The length of the conventional spliced $\mathrm{d}$ unspliced transcripts are shown along with several mutant quences detected. However, several unusual spliced products re also identified where several base pairs were missing from e sequence. In particular, this occurred for some GL-V $\beta 5.2$ $\mathrm{d}$ GL-V $\beta 8.3$ gene products. In the case of GL-V $\beta 5.2$, the inscript lacked 10 bp of the V $\beta 5.2$ coding exon, while for GL38.3, this lacked $32 \mathrm{bp}$ of the coding exon (Fig. 7). These small deletions were not recognisable on an ethidium-bromide stained gel but were detectable by DNA sequencing. The presence and therefore stability of these transcripts suggests that they were not degraded in the cell by nonsense-mediated decay (Gudikote and Wilkinson, 2002).

\subsection{Analysis of unspliced TCR components and alternative open reading frames}

Unspliced GL-V $\beta$ gene expression was prevalent in lymphoid tissues and in some cases was expressed at higher levels than the spliced counterpart. The presence of high levels of particular unspliced GL-V $\beta$ transcripts suggests a high level of transcript stability. It has been suggested that GL-V $\beta$ transcription is a sterile by-product of the rearrangement process (Sutton et al., 1998; Yancopoulos and Alt, 1985). However, the prevalence and stability of transcripts does not reconcile this hypothesis. In addition, truncated forms of GL-V $\beta$ transcripts lacking portions of sequence removed in the splicing process have also been identified (Fig. 7). While errors are known to occur both in transcription and in splicing, aberrant transcripts 


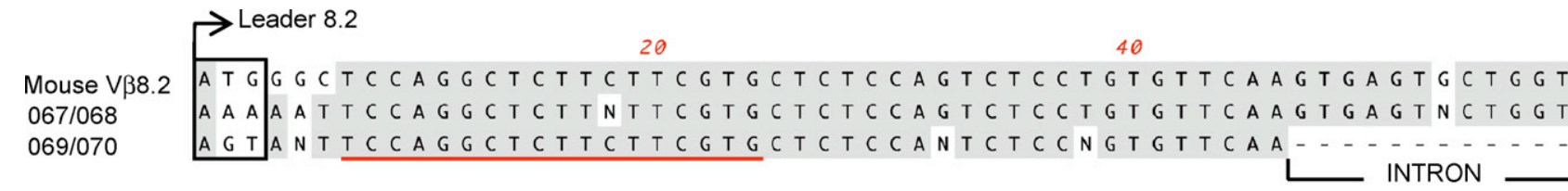
60 80 100

Mouse VB8.2 C A G G C C A C A G GTGTGCTTCTCTCTCCAGAATTCCCAAGTCTTTTTGCTAAGATGACAT 067/068 CAGGCCACAGGTGTGCTTCTCTCTCCAGAATTCCCAAGTCTTTTTGCTAAGATGACAT 069/070 C INTRON 120 160

Mouse VB8.2 C ATCAGGTTTTGTCTTTCTTTTTATAGAACACATGGAGGCTGCAGTCACCCAAAGCCC 067/068 CATCAGGTTTNGTCTTTCTTTTTATAGAACACATGGAGGCTGCAGTCACCCAAAGCCC 069/070 - . - . - . - INTRON

180 200 AACACATGGAGGCTGCAGTCACCCAAAGCCC $\rightarrow V \beta 8.2$ Exon 220

Mouse VB8.2 A A GA A CA A G G GG CA GTAACAGGAGGAAAGGTGACATTGAGCTGTAATCAGACTAAT 067/068 AAGAAACAAGGTGCAGTAACAGGAGGAAAGGTGACATTGAGCTGTAATCAGACTAAT $069 / 070$ A A G A A CAAGGTGGCAGTAACAGGAGGAAAGGTGACATTGAGCTGTAATCAGACTAAT

240

260
280

Mouse VB8.2 A A C C ACA ACA ACA T G T A T TGTATCGGCAGGACACGGGGCATGGGCTGAGGCTGATCC $067 / 068$ $069 / 070$ $A A C C A C A A C A A C A T G T A C T G G T A T C G G C A G G A C A C G G G G C A T G G G C T G A G G C T G A T C C$ A ACCNCAACAACATGTACTGGTATCGGCAGGACACGGGGCATGGGCTGAGNCTGATCC

300 320 340

Mouse V $\beta 8.2$ $067 / 068$ 069/070

A T T A T T-CATATGGTGCTGGCAGCACTGAGAAAGGAGATATCCCTGATGGATACAAGG

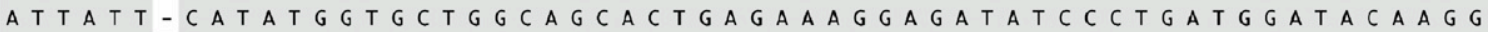
A T T A T T A A TATGGTGCTGGCAGCACTGAGAAAGGAGATATCCCTGATGGATACAAGG

360

380

400

Mouse VB8.2 C C T C CAGACCAAGCCAAGAGAACTTCTCCCTCATTCTGGAGTTGGCTACCCCCTCTCA 067/068 CCTCCAGACCAAGCCAAGAGAACTTCTCCCTCATTCTGGAGTTGGCTACCCCCTCTCA $069 / 070$ $C C T C C A G A C C A A G C C A A G A G A A C T T C T C C C T C A T T C T G G A G T T G G C T A C C C C C T C T C A$

420

440

Mouse VB8.2 G A C A T C A G T G T A C T T C T G T GC CA GCG GTGATGCACAGTGATGTGGGG

$067 / 068$

$069 / 070$

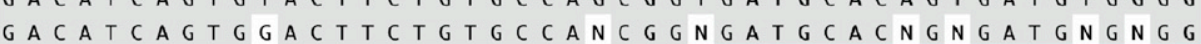

Fig. 5. Nucleotide sequence of spliced and unspliced L8.2-V $\beta 8$.2. The spliced and unspliced forms of V $\beta 8.2$ were cloned from the spleen derived cell line, C1V13D, and sequenced in the forward and reverse orientation and aligned. Forward and reverse sequences (unspliced: 067/068 and spliced: 069/070) were compared, combined and aligned against mouse V $\beta 8.2$ (NCBI accession no. AE000663) using ClustalW (MacVector 7.1). ATG start codons are boxed and the position of the primer is shown with a dashed line. The start of the Leader $(\mathrm{L})$ and the end of the V $\beta 8.2$ exon are shown by arrows. The intron in the L8.2 unspliced sequence is indicated.

are probably removed from the cell by nonsense-mediated decay (Gudikote and Wilkinson, 2002). Indeed germline transcripts have been identified for other TCR genes including TCR- $\delta$ (Shimamura and Ohta, 1995), TCR-C $\beta$ (Soloff et al., 1995; Wang et al., 1996), TCR-C $\beta$ (Wang et al., 1996; Lee et al., 2001), TCR-V $\alpha$ (Fondell and Marcu, 1992; Holman et al., 1993), and TCR-C $\gamma$ (Goldman et al., 1993). Since unspliced and spliced GL-V $\beta$ transcripts appear to be common and quite stable, the question can be raised as to whether unspliced transcripts encode an alternative protein product to TCR-V $\beta$. Bioinformatic analysis was conducted to examine unspliced GL-V $\beta$ gene sequences containing the $\mathrm{L}$, intron and $\mathrm{V} \beta$ coding exons for alternative open reading frames (ORFs) that could encode a new peptide. Sequences were used in a Blast-X search of the NCBI database and homologous sequences sought. Alter- native ORFs identified for the V $\beta 5$ and $V \beta 8$ family of genes, and homologous sequences in the database were identified. Translated sequence generated from alternative ORFs showed significant homology with TCR-V $\beta$ genes. However, this was often in short segments and not over the entire ORF. Therefore similarity between the nucleotide sequence of the entire ORF and the NCBI Expressed Sequence Tag (EST) database was tested using 'nucleotide search' in BlastN 2.2.1. Some similarity between ORFs and sequences in the EST database was detected, with $E$ values ranging from E-160 to 0.28 (Table 2). The tissues from which homologous sequences were derived included neonatal thymus, adult epididymis and mammary glands. High sequence similarity suggests that the ORFs are expressed, but again, detection of only small stretches of sequence were found. 


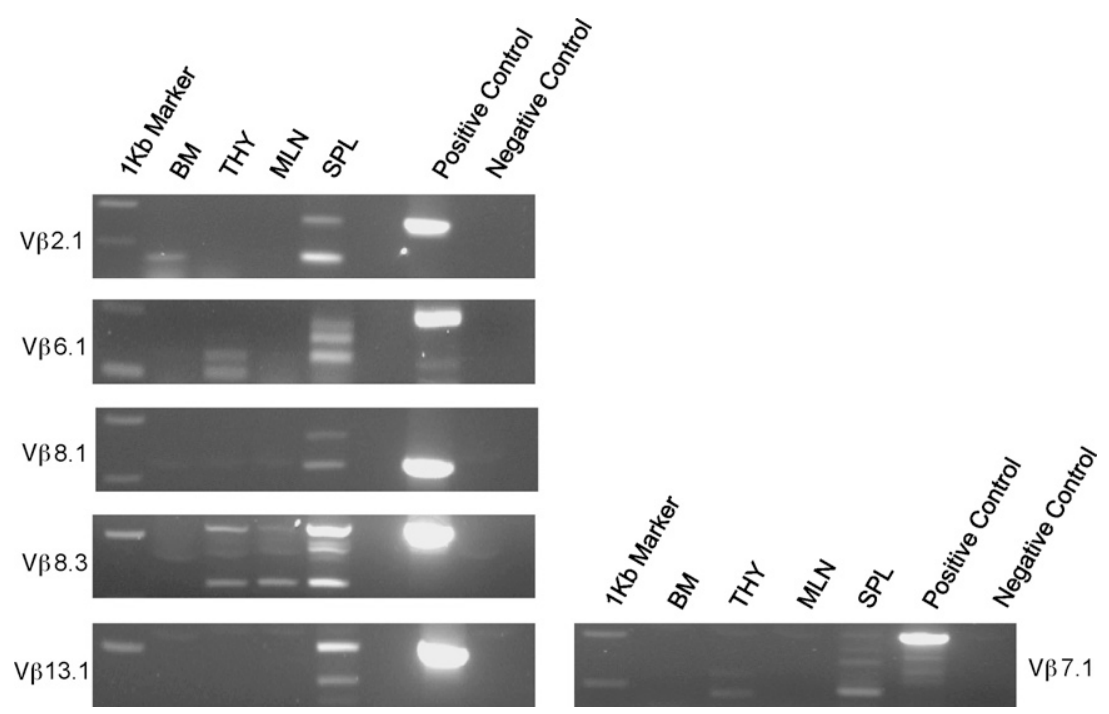

6. The expression of germline TCR-V $\beta$ s in lymphoid tissues of DBA/2j mice. The EtBr-stained gel shows RT-PCR products generated from bone marrow (BM), senteric lymph node (MLN), thymus (THY) and spleen (SPL) cDNA using primer sets which amplify only germline and not rearranged transcripts encoded by a ge of different TCR-V $\beta$ genes. Control reactions contained genomic DNA (positive control) and no DNA (negative control). Gene Ruler 1 kb DNA Ladder was d as a marker.

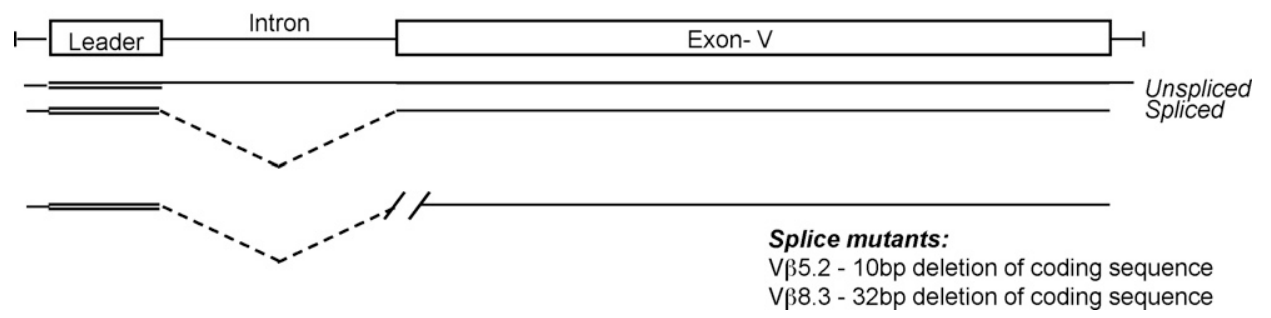

7. Schematic representation of mutant TCR-V $\beta$ genes identified. The derivation of unspliced and spliced forms is shown. The position of the leader (L) and $\mathrm{V}$ on is indicated and solid lines indicate gene sequence, while dotted lines represent exon splicing. The line breaks in the mutant sequence represent deletions.

ole 2

mology between alternative ORFs in the V $\beta 5$ and $\mathrm{V} \beta 8$ gene families and sequences within the NCBI EST database

\begin{tabular}{|c|c|c|c|c|}
\hline $\mathrm{R}-\mathrm{V} \beta$ gene & ORF & NCBI accession no. & Clone source $^{\mathrm{a}}$ & $E$ value $^{\mathrm{b}}$ \\
\hline \multirow{2}{*}{5.1} & -2 & BB588257 & Sixteen-day neonatal thymus cDNA & $E=2 \mathrm{E}-40$ \\
\hline & -3 & BB588257 & Sixteen-day neonatal thymus cDNA & $E=5 \mathrm{E}-51$ \\
\hline \multirow[t]{2}{*}{5.2} & +1 & BB584178 & Adult male epididymis cDNA & $E=6 \mathrm{E}-30$ \\
\hline & -2 & BB584178 & Adult male epididymis cDNA & $E=3 \mathrm{E}-26$ \\
\hline \multirow[t]{2}{*}{8.1} & +1 & AI182165 & Soares mammary gland cDNA & $E=3 \mathrm{E}-62$ \\
\hline & +4 & BF65872 & Soares thymus mouse cDNA & $E=6 \mathrm{E}-13$ \\
\hline \multirow[t]{4}{*}{8.2} & +1 & AI182165 & Soares mammary gland cDNA & $E=3 \mathrm{E}-84$ \\
\hline & -2 & BB588339 & Sixteen-day neonate thymus cDNA & $E=3 \mathrm{E}-33$ \\
\hline & +3 & BF65872 & Soares thymus mouse cDNA & $E=1 \mathrm{E}-35$ \\
\hline & -4 & AI182165 & Soares mammary gland cDNA & $E=4 \mathrm{E}-57$ \\
\hline \multirow{4}{*}{8.3} & -4 & AI182165 & Soares mammary gland cDNA & $E=7 \mathrm{E}-99$ \\
\hline & -5 & AI182165 & Soares mammary gland cDNA & $E=1 \mathrm{E}-72$ \\
\hline & +6 & AI182165 & Soares mammary gland cDNA & $E=3 \mathrm{E}-54$ \\
\hline & +7 & BB452046 & Twelve-day embryo spinal ganglion cDNA & $E=0.28$ \\
\hline
\end{tabular}




\subsection{Detection of intronic sequences in EST database}

The prevalence of unspliced transcripts in murine tissues raised the question of whether the intron between the $\mathrm{L}$ and $\mathrm{V} \beta$ exon is also represented in the NCBI EST Database. Intronic sequences between the $\mathrm{L}$ and $\mathrm{V}$ coding exons of $\mathrm{V} \beta 5$ and $\mathrm{V} \beta 8$ family genes were examined for sequence similarity with clones in the NCBI EST database. $E$ values detected for the majority of $\mathrm{V} \beta$ introns were not significant. The V $\beta 8.2$ intron displayed significant homology with a cDNA library clone from hematopoietic stem cells (HSC) (NCBI accession no. CF910965) ( $E$ value of 9E-18). This suggests that HSC, whose TCR- $\beta$ locus is in germline configuration, may also express germline transcripts of V $\beta 8.2$ in unspliced form. The intronic region was translated and the sequence tested for similarity within the NCBI protein database using Tblastn. This analysis revealed $100 \%$ homology with a TCR- $\beta$ locus sequence (AE000663.1) and $96 \%$ similarity with a V $\beta 8.2$ sequence (M15617.1). When the translated sequence from the intronic region upstream of the $\mathrm{L}$ sequence right through to the intronic region past the V $\beta 8.2$ exon was analysed using BlastP, similarity to only TCR- $\beta$ chain genes (L37869) was identified with an $E$ value of $2 \mathrm{E}-52$. This confirmed previous detection of unspliced GL-V $\beta 8.2$ transcripts.

\section{Discussion}

This report emphasises the prevalence of germline V $\beta$ transcription in multiple mouse strains and tissues. Previous analysis of germline transcription in murine tissues focused on V $\beta 8.2$, the most highly expressed germline transcript, predominantly when it is spliced to the very strong L5.1 promoter (Chou et al., 1987; Sutton et al., 1998). Germline transcription of a range of $\mathrm{V} \beta$ genes has now been detected in bone marrow, thymus, mesenteric lymph node and spleen using primers that span the intron/exon boundary and distinguish germline from rearranged transcripts. These tissues also show rearranged transcripts detectable with different primers. In many cases, multiple transcripts were detected representing both spliced and unspliced forms of the germline V $\beta$ transcript. For most genes, the expression of spliced and unspliced forms was equivalent, except for V $\beta 8.3$ in spleen and V $\beta 13.1$ in mesenteric lymph node and spleen, where the unspliced form predominated. Unspliced germline transcripts have previously been identified for TCR-V $\alpha 8$, TCR- $\delta$ and $\mathrm{Ig}-\mathrm{V} \kappa$ genes (Holman et al., 1993; Shimamura and Ohta, 1995; Thompson et al., 1998). High levels of L8.2-V $\beta 8.2$ and V $\beta 8.3$ have been previously associated with promoter strength (Chen et al., 2001; Chou et al., 1987; Sutton et al., 1998). In that study, L8.2-V $\beta 8.2$ was predominantly expressed, producing levels of germline transcripts approximately one-tenth that of rearranged genes in B6 thymocytes (Chen et al., 2001). Germline V $\beta 8.3$, however, was not as strongly expressed by comparison with $\mathrm{V} \beta 8.2$, but was still produced at a higher rate than some other $\mathrm{V} \beta$ genes, at a rate approximately one-fiftieth that of rearranged genes in B6 thymocytes (Chen et al., 2001). The high level of germline V $\beta 8.2$ and V $\beta 8.3$ transcripts may reflect active promoters pro- ducing transcripts at a faster rate than the splicing machinery can process.

The presence of a wide range of germline $\mathrm{V} \beta \mathrm{s}$ in murine tissues suggests that these transcripts do not contain a premature termination codon. Spliced and unspliced forms of the same germline $\mathrm{V} \beta$ gene were detected in both $\mathrm{C} 57 \mathrm{BL} / 6 \mathrm{~J}$ and $\mathrm{DBA} / 2 \mathrm{j}$ mice. While DBA/2j mice expressed multiple $\mathrm{V} \beta$ genes as germline transcripts, the level and range was lower than in C57BL/6J mice. Lower levels of germline V $\beta 8.1$ in thymus, and V $\beta 8.3$ in spleen and thymus of DBA/2j mice, by comparison with $\mathrm{C} 57 \mathrm{BL} / 6 \mathrm{~J}$ mice, also agrees with a previous report (Jolly and O'Neill, 1997). The variation in expression pattern of GL transcripts between strains could be attributed to genetic differences, perhaps promoter strength, and even TCR-V $\beta$ usage preferences between strains. This study shows no evidence to support a model that GL-V $\beta$ transcription in developing $\mathrm{T}$ cells may direct TCR-V $\beta$ usage.

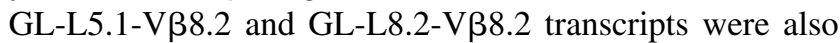
present in lymphoid tissues of $\beta_{2} \mathrm{M}^{-/-}$mice. The clear loss of CD1-dependent NK1.1 T cells is therefore not solely responsible for germline V $\beta 8.2$ transcription in C57BL/6J mice. Analysis of germline $\mathrm{V} \beta$ transcription in bone marrow, thymus, mesenteric lymph node and spleen revealed some differences in the level of GL-L8-V $\beta 8.2$ transcripts in bone marrow and spleen of $\beta_{2} \mathrm{M}^{-/-}$ and wild-type mice. $\beta_{2} \mathrm{M}^{-1-}$ mice displayed an increase in bone marrow and a decrease in spleen for germline L8-V $\beta 8.2$ consistent with loss of $\mathrm{CD}^{+} \mathrm{T}$ cells in spleen. There also appears to be an accumulation of transcripts in bone marrow perhaps due to a block in cell development attributable to the absence of MHC Class I expression. Studies by others have shown that the absolute number of NK1.1 T cells is halved in the bone marrow of $\beta_{2} \mathrm{M}^{-1-}$ mice (Zeng et al., 1999). This must be considered in terms of the various subtypes of NK T cells. The $\mathrm{CD}^{+}$cells decrease from $7.7 \%$ in the wild-type to $2.1 \%$ in $\beta_{2} \mathrm{M}^{-/-}$mice. $\mathrm{CD}^{+} \mathrm{NK}$ T cells decrease from $13.2 \%$ in wildtype to $0.3 \%$ in the knock-out. However, $\mathrm{CD}^{-}{ }^{-} \mathrm{CD} 8^{-} \mathrm{NK} 1.1 \mathrm{~T}$ cells remain virtually unaltered and therefore may recognise a $\mathrm{CD} 1$ form that is independent of $\beta_{2}$-microglobulin, with levels of $15.6 \%$ in wild-type bone marrow and $14.4 \%$ in the $\beta_{2} \mathrm{M}^{-1-}$ knockout (Zeng et al., 1999). Evidence presented here supports a $\beta_{2} \mathrm{M}$-independent mechanism for germline TCR-V $\beta$ gene transcription since GL-V $\beta$ transcripts are still expressed albeit in different levels.

Germline L8.2-V $\beta 8.2$ transcription was also found to decrease in the spleen of $\beta_{2} \mathrm{M}^{-I-}$ mice. Since the NK1.1 T cell population in spleen only accounts for $0.5-1 \%$ of cells (Bendelac et al., 1997), this decrease is probably a reflection of the effects of a dysfunctional $\beta_{2} \mathrm{M}$ gene on development of other cell subsets like $\mathrm{CD}^{+} \mathrm{T}$ cells. However, CD1 expression has also been noted on $\mathrm{B}$ cells in $\mathrm{C} 57 \mathrm{BL} / 6 \mathrm{~J}$ mice and is shown to affect numbers of $\mathrm{CD}^{+}{ }^{+} \mathrm{B} 220^{+}$cells in $\beta_{2} \mathrm{M}^{-/-}$mice (Amano et al., 1998; Brossay et al., 1997). While this effect was not observed in lymph node or bone marrow, numbers in spleen, decreased from $16 \%$ in C57BL/6J mice to $0.2 \%$ in $\beta_{2} \mathrm{M}^{-l-}$ mice (Amano et al., 1998). CD1-expressing cells in spleen include follicular, marginal zone and immature/B-1 B cells. However, follicular and marginal B cells remained unaltered in $\beta_{2} \mathrm{M}^{-l-}$ mice, again suggesting a 
D1-independent developmental pathway (Amano et al., 1998). noted in our previous studies, germline $V \beta$ transcription has en identified in immature and early B cells (Candeias et al., 94; Jolly and O'Neill, 1997). The clear loss of CD1-dependent $\mathrm{K} 1.1 \mathrm{~T}$ cells and $\mathrm{CD} 8^{+} \mathrm{T}$ cells in $\beta_{2} \mathrm{M}^{-/-}$mice, combined with loss of any immature B cells from the spleen, may account $r$ the decrease in germline V $\beta 8.2$ transcription in spleen of $\mathrm{M}^{-1-}$ mice.

The stability and prevalence of germline transcripts in mulle tissues of several mouse strains raises questions about hether these transcripts have a functional role in vivo. While have identified cell surface expression of germline-encoded 38.2 peptides using antibody binding, expression is weak and munoprecipitation studies have not been informative with ailable antibodies (Abbey et al., 2006; Jolly and O'Neill, 95). However, the possibility that multiple germline-encoded 3 peptides are expressed on the cell surface is difficult to reccile. For this reason, the possibility that germline $V \beta$ genes code alternative ORFs within both introns and exons was conlered. Investigations revealed many alternative ORFs within nes of the V $\beta 5$ and V $\beta 8$ families. Examination of similarfor the translated ORF sequences using the NCBI protein tabase revealed homology to only TCR $\beta$ chain proteins. It ems unlikely therefore that these ORFs would encode unreed proteins. Further analysis of similarity between ORFs in V V $\beta 5$ and V $\beta 8$ gene families and the NCBI EST database owed high sequence homology for short regions of sequence th cDNA clones in this database. The clones that displayed nilarities were often repetitive between genes, suggesting a gh level of evolutionary relatedness between and within V $\beta 8$ d V $\beta 5$ family genes.

The presence of unspliced germline $V \beta$ transcripts in mulle lymphoid tissues is relevant to recent evidence for the le of non-coding introns in mammals (Mattick and Makunin, 06; Szymanski and Barciszewski, 2006). It questions whether spliced transcripts or transcribed introns have any functional le. Analysis of the similarities between introns in the V $\beta 5$ $d V \beta 8$ gene families and the NCBI database revealed no sigficant homology for any of the introns, with the exception the V $\beta 8.2$ intron. This intron gave an $E$ value of $9 \mathrm{E}-18$ th high sequence similarity to a cDNA clone from an HSC rary. Non-protein coding RNA could have a developmenrole in regulating mRNA turnover of TCR- $\beta$ genes, timing TCR $\beta$ chain expression, or even transcription and splicing rearranged TCR genes. It may also function in regulating romatin accessibility for VDJ recombination. Such a model plausible with the recent identification of developmentally pressed germline sense and antisense IgVHJ558 transcripts olland et al., 2004), together with accumulating evidence for e role of non-protein-coding RNA in other systems (Mattick d Makunin, 2006; Szymanski and Barciszewski, 2006).

\section{cknowledgements}

This work was supported by a grant from the National Health d Medical Research Council of Australia to HO.

\section{References}

Abbey, J.L., Hulett, M., O’Neill, H.C., 2006. Cell surface expression of a peptide encoded by the unrearranged TCR-Vbeta8 2 gene. Mol. Immunol. 43, $1408-1417$.

Abbey, J.L., O'Neill, H.C., 2004. Germline transcription of multiple TCR-Vbeta genes in cloned T-cell lines. Immunol. Cell Biol. 82, 393-399.

Amano, M., Baumgarth, N., Dick, M.D., Brossay, L., Kronenberg, M., Herzenberg, L.A., Strober, S., 1998. CD1 expression defines subsets of follicular and marginal zone B cells in the spleen: beta 2-microglobulin-dependent and independent forms. J. Immunol. 161, 1710-1717.

Arase, H., Arase, N., Ogasawara, K., Good, R.A., Onoe, K., 1992. An NK1.1+ CD4+8- single-positive thymocyte subpopulation that expresses a highly skewed T-cell antigen receptor V beta family. Proc. Natl. Acad. Sci. U.S.A. 89, 6506-6510.

Bendelac, A., Rivera, M.N., Park, S.H., Roark, J.H., 1997. Mouse CD1-specific NK1 T cells: development, specificity, and function. Annu. Rev. Immunol. $15,535-562$.

Bolland, D.J., Wood, A.L., Johnston, C.M., Bunting, S.F., Morgan, G., Chakalove, L., Fraser, P.J., Corcoran, A.E., 2004. Antisense intergenic transcription in V(D)J recombination. Nat. Immunol. 5, 630-637.

Brossay, L., Jullien, D., Cardell, S., Sydora, B.C., Burdin, N., Modlin, R.L., Kronenberg, M., 1997. Mouse CD1 is mainly expressed on hemopoieticderived cells. J. Immunol. 159, 1216-1224.

Bustin, S.A., 2000. Absolute requirements of mRNA using real-time reverse transcription polymerase chain reaction assays. J. Mol. Endocrin. 25, 169-193.

Candeias, S., Hardy, R.R., Li, Y.S., Staerz, U.D., 1994. T cell receptor V beta 8,2 gene germ-line transcription: an early event of lymphocyte differentiation. Eur. J. Immunol. 24, 3073-3081.

Chen, F., Rowen, L., Hood, L., Rothenberg, E.V., 2001. Differential transcriptional regulation of individual TCR V beta segments before gene rearrangement. J. Immunol. 166, 1771-1780.

Chou, H.S., Anderson, S.J., Louie, M.C., Godambe, S.A., Pozzi, M.R., Behlke, M.A., Huppi, K., Loh, D.Y., 1987. Tandem linkage and unusual RNA splicing of the T-cell receptor beta-chain variable-region genes. Proc. Natl. Acad. Sci. U.S.A. 84, 1992-1996.

Coles, M.C., Raulet, D.H., 1994. Class I dependence of the development of CD4+ CD8- NK1.1+ thymocytes. J. Exp. Med. 180, 395-399.

Fondell, J.D., Marcu, K.B., 1992. Transcription of germline V $\alpha$ segments correlates with ongoing T-cell receptor $\alpha$-chain rearrangement. Mol. Cell Biol. $12,1480-1489$.

Gudikote, J.P., Wilkinson, M.F., 2002. T-cell receptor sequences that elicit strong down-regulation of premature termination codon-bearing transcripts. EMBO J. 21, 125-134.

Goldman, J.P., Spencer, D.M., Raulet, D.H., 1993. Ordered rearrangement of variable region genes of the T cell receptor $\gamma$ locus correlates with transcritiption of the unrearranged genes. J. Exp. Med. 177, 729-739.

Holman, P.O., Roth, M.E., Huang, M., Kranz, D.M., 1993. Characterization of transcripts from unrearranged $\mathrm{V}$ alpha 8 genes in the thymus. J. Immunol. 151, 1959-1967.

Jolly, C.J., O'Neill, H.C., 1995. Expression of a TCR V beta 8,2 polypeptide from the unrearranged gene in a murine lymphoid precursor cell line. Int. Immunol. 7, 1147-1156.

Jolly, C.J., O'Neill, H.C., 1997. Specific transcription of the unrearranged TCR $\mathrm{V}$ beta 8,2 gene in lymphoid tissues occurs independently of $\mathrm{V}(\mathrm{D}) \mathrm{J}$ rearrangement. Immunol. Cell Biol. 75, 13-20.

Lee, H.C., Ye, S.K., Honjo, T., Ikuta, K., 2001. Induction of germline transcription in the human TCR $\gamma$ locus by STAT5. J. Immunol. 144, 19831987.

Mattick, J.S., Makunin, I.V., 2006. Non-coding RNA. Hum. Mol. Genet. 15, R17-R29.

O'Neill, H.C., 1992. Unique lymphoid cell subset target to infection and proliferation induced in vitro by a murine leukemia virus. Leukemia 6,272 281.

O’Neill, H.C., Jolly, C.J., 1995. Germline transcription and expression of Tcrb-V8 genes in peripheral mouse lymphoid tissues. Immunogenetics 42 , 309-314. 
Ohteki, T., MacDonald, H.R., 1994. Major histocompatibility complex class I related molecules control the development of CD4+8- and CD4-8- subsets of natural killer $1.1+\mathrm{T}$ cell receptor-alpha/beta+ cells in the liver of mice. J. Exp. Med. 180, 699-704.

Shimamura, M., Ohta, S., 1995. Germ-line transcription of the T cell receptor delta gene in mouse hematopoietic cell lines. Eur. J. Immunol. 25, 1541-1546.

Soloff, R.S., Wang, T.G., Lybarger, L., Dempsey, D., Chervenak, R., 1995. Transcription of the TCR- $\beta$ locus initiatives in adult murine bone marrow. J. Immunol. 154, 3888-3901.

Sutton, K.A., Vu, M.N., Wilkinson, M.F., 1998. Distal V beta promoters transcribe novel T-cell receptor-beta transcripts in early development. Immunology 93, 213-220.

Szymanski, M., Barciszewski, J., 2006. RNA regulation in mammals. Ann. N. Y. Acad. Sci. 1067, 461-468.

Thompson, A., Brouns, G.S., Schuurman, R.K., Borst, J., Timmers, E., 1998. A pro-B-cell stage characterized by germline Ig transcription without surrogate light chain expression. Immunogenetics 48, 305-311.
Thompson, J.D., Higgins, D.G., Gibson, T.J., 1994. CLUSTAL W: improving the sensitivity of progressive multiple sequence alignment through sequence weighting, position-specific gap penalties and weight matrix choice. Nucleic Acids Res. 22, 4673-4680.

Wang, J.H., Nichogiannopoulou, A., Wu, L., Sun, L., Sharpe, A.H., Bigby, M., Georgopoulos, K., 1996. Selective defects in the development of the fetal and adult lymphoid system in mice with an Ikaros null mutation. Immunity 5, 537-549.

Yancopoulos, G.D., Alt, F.W., 1985. Developmentally controlled and tissuespecific expression of unrearranged VH gene segments. Cell 40, 271281.

Zeng, D., Gazit, G., Dejbakhsh-Jones, S., Balk, S.P., Snapper, S., Taniguchi, M., Strober, S., 1999. Heterogeneity of NK1.1+ T cells in the bone marrow: divergence from the thymus. J. Immunol. 163, 5338-5345.

Zijlstra, M., Bix, M., Simister, N.E., Loring, J.M., Raulet, D.H., Jaenisch, R., 1990. Beta 2-microglobulin deficient mice lack CD4-8+ cytolytic T cells. Nature 344, 742-746. 